[Chapman, T. (2000). Managing Teacher Performance in Today's Schools. New Zealand Annual Review of Education, 9, 43-62]

\section{Managing Teacher Performance in Today's Schools}

\author{
TRICIA CHAPMAN
}

\section{Abstract:}

The Tomorrow's Schools reforms created confusion as to exactly who is the employer of teachers. In terms of the 1989 Education Act, it is the Board of Trustees. In practice, hiring and firing is likely to be done by the principal, and the Ministry of Education represents the employer party in collective employment contract negotiations. Drawing on the author's personal experience of managing Ministry of Education contracts in performance management, this article:

- considers whether the imposed requirements for the performance management of teachers are consistent with the self-managing school framework; and

- evaluates the effectiveness of the regulations in enhancing teacher performance.

$\mathrm{W}$ re the Tomorrow's Schools reforms of educational administration about devolution or decentralisation? These themes have been much analysed, but rarely from a "board as employer" perspective.

This paper investigates a key aspect of the employer role, teacher performance management. The legal requirements are examined to determine whether they are consistent with the central construct of the reforms, the self-managing school. The effectiveness of the regulations as a strategy for enhancing teacher performance is also explored.

The Tomorrow's Schools reforms created confusion as to who is the employer of teachers. The 1989 Education Act (Section 65) states "a Board (of Trustees) may from time to time, in accordance with the State Sector Act 1988, appoint, suspend, or dismiss staff." In practice the "hiring and firing" is likely to be done at arm's length through its chief

\section{Tricia Chapman}

executive, the principal. At the same time the state, through the Ministry of Education, retains the role of negotiating collective employment contracts (CECs) with the teacher unions - the New Zealand Educational Institute (NZEI), and the Post-Primary Teachers' Association (PPTA). The CECs determine working conditions and rates of pay. Boards that have opted for bulk funding of teacher salaries may choose to negotiate site contracts. However such agreements still have to be approved by the Ministry of Education.

The issue of performance management of teachers highlights this lack of clarity. Improved teacher performance is a key to policy initiatives for raising student performance. The "self-managing" school must implement procedures that meet imposed requirements for performance appraisal (PMS), assessment against professional standards (PS) and Teacher Registration Board (TRB) criteria for a satisfactory teacher.

\section{Performance Management Policy Development 1988-1999}

The changes to the administration of education known as the Tomorrow's Schools reforms were part of government policy for public sector reform in the late 1980s. These changes were based on the premise that adoption of private sector management practice, and introduction of competition into the public sector, would lead to greater effectiveness and efficiency. A stated intent of the reforms of school administration was to encourage greater local decision making about education through "partnership between the professionals and the particular community in which it is located. The mechanism for such a partnership will be a Board of Trustees" (MOE, 1988, p. 1).

The 1989 Education Act expanded on how "partnership" was to work: "a school's board has complete discretion to control the management of the school as it thinks fit" (Section 75); "a school's principal is the board's chief executive in relation to the school's control and management and has complete discretion to manage as the principal thinks fit the school's day to day administration" (Section 76).

These words have been much debated in the ensuing decade and may yet be revised. Certainly the use of the word "control" seems at odds with the concept of partnership and a governance/management relationship. In practice it has been interpreted as the whole board, including the principal, determining the parameters within which the principal has day to day control of the school. As well as being the board's chief executive, the principal is the professional leader of the 
school. It is the board, through its charter, that is accountable for ensuring that the National Curriculum is delivered in a safe environment by competent teachers. In 1995 the Education Review Office (ERO) concluded that: "Managing staff performance in schools is fundamental to the delivery of high quality education. Only when each board manages its own staff effectively can parents be assured that a high quality education is being provided for their children in their school (ERO, 1995, p. 24).

The ERO's view echoed findings in the 1994 report of the Working Group on Primary Teacher Pay, Performance and Accountability (Deloitte Touche Tohmatsu, 1994). ERO's role is to determine whether the board of trustees of each school has complied with its legal obligations. This task is assisted by the existence of clear criteria that must be met. In its view, these had not been made sufficiently explicit in regard to teacher performance. Many schools had yet to implement performance appraisal. A 1992 survey of Auckland and Northland secondary schools showed only 35 percent had formal appraisal systems (Peer \& Inkson, 1993 cited in Timperley \& Robinson, 1996, p. 22).

Provision for such criteria to be developed had been made in the 1988 State Sector Act which permits the Secretary for Education to "prescribe matters that are to be taken into account by employers in assessing the performance of teachers" (Sec. 77c). The 1993 National Administration Guidelines (NAGs) also make reference to this area. NAG 2 required boards to "promote high levels of staff performance." In ERO's opinion, many boards needed clearer direction as to what this entailed.

The apparent lack of specificity regarding performance management during the early 1990's is consistent with the "hands off" policy that existed within the Ministry of Education during this period. By the mid-1990's there were signs this was beginning to change. Protection of the government's "ownership interest" has been suggested as a motive for this shift (State Services Commission, cited in Barrington, 1997, p. 89). An inter-departmental Officials Group was formed to investigate and develop recommendations for the management of teacher performance. It was chaired by Treasury Official Howard Fancy, who was to become Secretary for Education in 1997 after a stint as CEO of the Ministry of Commerce. The group reviewed practice in similar types of education systems, as well as in the public and private sectors. The outcome of its deliberations was a 39 page booklet: Draft National Guidelines For Performance Management in Schools (MOE, 1995).
During 1996 the Ministry contracted providers to:

- introduce the draft guidelines to principals and boards of trustees; - examine how schools might implement systems in line with the draft guidelines;

- elicit the views of principals and boards on the guidelines and their likely impact;

- make recommendations on any measures needed to support schools in their implementation.

As co-ordinator of one such contract in the Wellington region, the author was able to observe the sector's response to the "guidelines". Principals and trustees of schools with performance appraisal processes in place were concerned about having to start again using someone else's criteria. Some rewrote job descriptions to conform with the six Key Performance Areas. Schools in the process of developing a system used these as the basis for their documentation. Others adopted a "wait and see" approach. Many participants in the workshops and information meetings were sceptical about the degree to which these were a draft and the extent to which the process constituted consultation. However by late 1996 most had to admit that the Ministry did act on the feedback.

Two main outcomes of this period of consultation were:

1. Streamlining of the guidelines to a single page of requirements, legally enforceable from the start of the 1997 school year

The author participated in Ministry of Education meetings of contract providers where the wording for the final requirements was carefully crafted. Six "Key Performance Areas" (MOE, 1995) were replaced with three broad performance areas directly related to teachers' professional responsibilities: teaching, school-wide and management. Much thought went into the provision of examples for these. The words "such as" were used to convey their non-prescriptive nature. The aim was to allow boards and principals to select and target areas for focus, based on a teacher's strengths/weaknesses, the stage of their career, the needs of their students, and syndicate, departmental or school goals.

\section{Recognition of the training and resourcing implications for schools in} implementing systems based on the legal requirements

It may not have been as much as boards wanted, but the Ministry did come up with extra dollars. During 1997 there was "a one-off payment of \$4 (GST inclusive) per student", with an additional \$500 for schools 
receiving targeted rural funding. Per pupil rates increased by $5 \%$ from 1998 in recognition of "a range of cost pressures including the on-going requirements of performance management" (MOE, 1997a, p. 2)

A series of five "PMS Supplements" (MOE, 1997b), providing exemplars and ideas to assist implementation, was distributed through the Education Gazette during 1997.

During 1998, Appraisal Skills for Teachers training was made available through professional development contracts. The programme offered to around 300 schools by Wellington College of Education provided the option of training key teachers, or in-house facilitated sessions for all teachers. Just under half of the schools opted to participate. The main reasons principals gave for declininginvolvement were:

- Staff are fully committed with other types of in-service; and/or

- Present appraisal system is working well and skill development is not needed.

\section{Professional Standards for Primary Teachers}

It was into such an environment that a new element, professional standards, was introduced through Collective Employment Contracts. At the same time as the appraisal skills programmes were getting underway, the Ministry was in negotiation with the primary teachers' union. NZEI's key objective was pay parity with secondary teachers. In return for this it bought into professional standards for beginning, fully registered and experienced teachers. These standards bear a close resemblance to the discarded Key Performance Areas of the $1996 \mathrm{draft}$ (Figure 1). Standards were also implemented for principals, deputy and assistant principals.

The Terms of Settlement (1998, p. 49) acknowledged that the standards "used for the purpose of pay progression" were interim ones likely to be subject to review and revision, particularly in the event of a teaching professional body being established as proposed in the Teacher Education Green Paper (MOE, 1997c). In order to progress in salary, the contract requires teachers be assessed against professional standards.
Figure 1 Comparison of the 1995 Key Performance Areas with Professional Standards

\begin{tabular}{|l|l|l|}
\hline $\begin{array}{c}\text { 1995: Draft Key } \\
\text { Performance Areas }\end{array}$ & $\begin{array}{c}\text { 1998: Interim Professional } \\
\text { Standards (Primary) }\end{array}$ & $\begin{array}{c}\text { 1999: Professional Standards } \\
\text { (Secondary) }\end{array}$ \\
\hline 1. Teaching strategies & 1. Professional knowledge & 1. Professional knowledge \\
\hline & & 2. Professional development \\
\hline 2. Curriculum delivery & 2. Teaching techniques & 3. Teaching techniques \\
\hline 3. Motivation of students & 3. Motivation of students & 4. Motivation of students \\
\hline 4. Classroom management & 4. Classroom management & 5. Student management \\
\hline & 5. Communication & 6. Effective communication \\
\hline $\begin{array}{c}\text { 5. Contribution to teaching } \\
\text { team activities }\end{array}$ & $\begin{array}{c}\text { 6. Support for and cooper- } \\
\text { ation with colleagues }\end{array}$ & $\begin{array}{l}\text { 8. Support for and cooper- } \\
\text { ation with colleagues }\end{array}$ \\
\hline $\begin{array}{c}\text { 6. Contribution to corpor- } \\
\text { ate life of the school }\end{array}$ & $\begin{array}{c}\text { 7. Contribution to wider } \\
\text { school activities }\end{array}$ & $\begin{array}{l}\text { 9. Contribution to wider } \\
\text { school activities }\end{array}$ \\
\hline
\end{tabular}

In April 1998 the Ministry informed boards that from the beginning of 1999 "appraisal will be required to be undertaken against all of the professional standards at the appropriate level" (MOE, 1998a, p. 3). The requirement to assess annually against professional standards as part of the appraisal strand of performance management extended to all teachers, regardless of their eligibility for pay progression.

The author corresponded with the Ministry in an effort to clarify the legal basis for requiring formative appraisal for professional development to be combined with summative assessment for salary progression. The response acknowledged that "some schools will decide to keep their formative appraisal process, with the developmental focus, separate from the summative assessment processes", i.e., against professional standards. However it then appeared to contradict this by saying "a school does not have the flexibility to determine which strand of the performance management system it will use" (to assess standards), because "schools will only meet the mandated PMS 
requirements as long as all teachers are assessed against all Professional Standards every year" (MOE, 1998d).

Clarification was also sought from the Ministry (1999a) as to whether the integration of professional standards into appraisal is consistent with the Principles of the PMS requirements (NZ Gazette, 1996, Sec. 3.1). Could nationally prescribed standards be said to be "appropriate to individual teachers, the school and wider community", to have been "developed in a consultative manner with teachers" and to have "a professional development orientation"? The response given suggested the professional standards supersede or over-ride the Principles. Nonetheless, they remain part of the legally mandated requirements.

\section{Professional Standards for Secondary Teachers}

The introduction of professional standards was a major sticking point in the protracted negotiations between the Ministry and the Post-Primary Teachers' Union during 1998 and the first half of 1999. The PPTA maintained research findings were inconclusive as to the effectiveness of "narrowly defined elements which purport to measure successful teaching" (PPTA, 1999, p. 2). In any case attestation criteria for pay progression had been in existence in Appendix $G$ of the contract since 1996. Eventually, after gaining some concessions in terms of the scope and wording of the standards, the PPTA conceded defeat and signed a contract giving teachers significant salary increases. From 2000, Appendix $\mathrm{G}$ is replaced by Professional Standards in nine dimensions (Figure 1).

Perceptions differ as to how these standards are to be implemented. The Ministry of Education sees them as providing "a framework for performance appraisal" (MOE, 1999c, p. 5) yet the Appendix G criteria, which they replace, have been assessed separately from the appraisal process in many colleges. The standards apply from the beginning of 2000. By 19 April, school management needs to have attested that they are being met in order for teachers to access the second tranche of the salary increase. PPTA sees this as a "one off" exercise as in future years attestation will only be required for teachers below the top of the scale (PPTA, 1999, p. 7). The Ministry expects boards to ensure every teacher is appraised against the appropriate set of standards annually. PPTA interprets the Ministry's requirement for "all standards" as "mischievous" from an industrial perspective (Cross, 1999). There are industrial pitfalls for boards "failing" a teacher for not meeting a particular standard when no previous concerns have been raised, and/or $\mathrm{s} /$ he has not received professional development to support its being met.

\section{Teacher Registration Board Criteria}

In addition to these requirements, the Teacher Registration Board has its own criteria for "satisfactory teachers" in four dimensions: professional knowledge, practice, relationships and leadership. Boards must have processes in place to determine whether beginning teachers meet criteria for registration after two years in the job, and whether other teaching staff meet criteria for three yearly re-registration. Since 1999 boards are required to employ registered teachers, although this can include the "limited authority to teach" category, which merely provides assurance of "fitness to teach", rather than professional competency (TRB, 1997). The Ministry sees the Professional Standards as going "beyond the minimum required for registration" (NZ Education Gazette, 1999, p. 12). NZEI see the standards as "essentially a sub-set" of TRB satisfactory teacher criteria (NZEI, 1998, p. 4). The good news for boards is that there is a reasonably close match between the two. It would be safe to assume that an effective process of standards assessment also provides assurance for registration purposes.

\section{Theory and Practice in Performance Management}

\section{Terminology}

The 1995 Draft Guidelines defined performance management as: "The process of identifying, evaluating and developing the work performance of employees in the organisation, so that the organisational goals and objectives are more effectively achieved, while at the same time benefiting employees in terms of recognition, receiving feedback, catering for work needs and offering career guidance" (Lansbury, 1988 cited in MOE, 1995, p. 5).

The mandatory PMS requirements adopted a broader definition which recognises that the appraisal and assessment of performance is only part of what an effective performance management system should encompass (NZ Gazette, 1996). Eight other bullet points are listed, including "those clauses of collective and individual employment contracts which relate to the performance management of staff" and "remuneration management", both of which could be seen as having a more direct link with Professional Standards than a school's appraisal system. 
Factors known to motivate performance

Professional standards were introduced as part of government strategy for "developing and maintaining high quality teaching and leadership in the education sector and improving learning outcomes for students" (MOE, 1998c). The aim is to effect change. This requires the development of a climate in which teachers are motivated to change. In any school, management must balance a culture in which teachers feel safe to try new things and acknowledge areas of weakness, with accountability - is the organisation meeting its obligations to the students and communities it serves, as well as to government and the tax payer?

Management literature identifies a number of motivation theories. Content theories relate to the needs of the individual. Herzberg's two-factor theory of job satisfaction is perhaps most relevant. In order to ensure motivated workers, jobs need to be "enriched" so that they provide opportunity for personal growth (Gilbert et al., 1995). This ties in with the Principles upon which the mandatory requirements for teacher performance appraisal are based.

Process theories concentrate on influences that affect the degree of effort individuals putinto tasks. Management by objectives (MBO) stresses the motivating effect of goal setting (Drucker, 1954). In its pure form, "MBO is a cascade system" where objectives determined at the top flow down to staff (Trethowan, 1987, p. 4). Professional standards could be seen in this context. School management can increase teacher ownership by developing site specific expectations derived from the standards, in consultation with staff. The PMS requirements include a form of MBO "target-setting". Teachers are required to set "at least one development objective" annually (NZ Gazette, 1996). The objective(s) take the individual's needs into account as well as those of the institution.

Adam's Equity Theory is based on individuals weighing up their own effort and reward in comparison to others (Gilbert et al., 1995). The lesson for management is to ensure fairness in the way employees are treated and rewarded. A concern teachers have expressed about professional standards linked to pay increments relates to consistency and fairness of process, both within a school and between schools.

A "sense of community spirit" has been identified as a "fundamental prerequisite to developing the capacity for change in individuals, institutions or societies" (Hallinger, 1997, p. 29). Planning change in advance "with a degree of detail that is simply inconsistent with reality" has its drawbacks. Change is more likely to happen when leaders are free to respond to what they learn, rather than depending on existing knowledge to control "people and the process to obtain the desired outcome" (Hallinger, 1997, p. 31). Current thinking about change also "suggests the importance of developing the school as a community of learners who share some common values and practices (i.e., rituals) about their role as life-long learners" (Hallinger, 1997, p. 32; see also: Fullan, 1991; Furukawa, 1994; Middlewood, 1997).

Vroom's Expectancy Theory introduces the concept of personal value (Gilbert et al., 1995). The individual's motivation to perform is related to his/her expectation of the outcome, and whether it will lead to rewards that are valued. A Ministry of Education manager sees Professional Standards as helping to replace an "entitlement culture" with one based on reward for results (MOE, 1999b). This supposes an entitlement culture exists and financial rewards are highly valued. The author has spoken with teachers who have decided that the pecuniary and status rewards of management positions do not adequately compensate for the additional pressures and stresses they bring. Promotion to management positions reduces interaction with students and a sense of doing something meaningful, which attracted many of them to the profession in the first place. Taking a wider perspective, many teachers are looking at the effort:reward ratio of teaching, comparing it to jobs in business or industry and concluding that more can be earned for less effort elsewhere.

These perceptions of the value teachers place on pecuniary reward are consistent with the finding of the Working Group on Primary Teachers' Pay, Performance and Accountability, that "teachers find their prime source of satisfaction in the intrinsic rewards of teaching". Salaries have significance in terms of "recruitment and retention, but cannot be expected to produce intense engagement or high performance" (Deloitte Touche Tohmatsu, 1994, p. 1). Some of this report's recommendations can be identified in subsequent policy initiatives. There is now a financial incentive for principals to document attestation of competence: their own increment depends on it. Professional standards could be seen as clarifying "performance measures and standards" (Deloitte Touche Tohmatsu, 1994, p. 36). Other findings in the report are less easily identified in the current environment. All professional standards must be met by every teacher every year. Although schools can link indicators to strategic direction, there is no attempt in the standards themselves to "assign weightings 
of relative importance to the various performance areas" (Deloitte Touche Tohmatsu, 1994, p. 7)

The report concluded: "The USA experience with merit pay suggests strongly that this is not an option that would produce either improved accountability or motivation in the New Zealand context." It went as far as to suggest such a move would be "highly likely to reduce the morale and commitment of most teachers." That this advice was seemingly ignored may be attributed to the political ideology underlying public sector reform in New Zealand. Barrington identifies the decentralisation of responsibility, coupled with increased control of "crucial powers" by central authority as an international trend in education. He perceives the "advocates of privatisation" as "the new players on centre stage" (1997, p. 91).

\section{The Impact on Schools}

At the beginning of 1998, boards had been expected to have PMS compliant systems in place for a year. The Teacher Appraisal Skills contract (TASC) programme, offered by Wellington College of Education, presented appraisal to teachers as their entitlement, rather than as something "done" to them. During the period leading up to the introduction of professional standards the TASC team saw considerable teacher "buy-in" to an appraisal process that:

- provides meaningful feedback on teaching performance;

- offers support for the achievement of professional development objectives that enhance job satisfaction and career opportunities;

- contributes to the improvement of teaching and learning.

The Ministry told Appraisal Skills providers they would probably have to alter programmes as a result of the introduction of Interim Professional Standards in the Primary Teachers' Contract (MOE, 1999a). In fact, the skills for participating in appraisal were made no less relevant, but the standards did bring about a significant change to the environment providers were working in. The sorts of questions asked of the TASC team were:

- Why bring in these extra requirements when teachers are still coming to terms with those imposed at the start of 1997 ?

- Can the Ministry require standards, brought in through contract negotiations, to be part of a school's appraisal process?

- Would such a system be consistent with the principles on which PMS requirements are based?
- What impact will standards assessment have on teacher commitment to existing appraisal processes?

- Where do the TRB "dimensions of a satisfactory teacher" fit?

- How on earth are we going to cope with it all?

An intermediate principal summed up how many of his colleagues were feeling: "In 1996 we reviewed our appraisal system against the draft guidelines, and re-wrote our job descriptions as a result. We did the same thing in 1997 when the Gazette statement came out. Now we have to look at where to fit Professional Standards into the picture, not to mention the TRB requirements and I honestly can't say that what we have is anything more effective than what we developed ourselves five years ago. If anything we are in danger of spending more time on the paperwork of the system than providing our teachers with professional support" (personal communication, February 4, 1999).

Other sources reinforce this view. A survey completed by 61 percent of secondary principals in March 1996 indicated all of them supported performance appraisal. Those who rated their system as highly effective commonly cited staff acceptance as a reason for this. The major difficulty was finding sufficient time to do appraisal properly (Timperley \& Robinson, 1996, p. 23). The extra demands of professional standards exacerbate this. A survey of 130 teachers from participating schools was conducted at the end of 1998 as part of the Appraisal Skills contract evaluation. Asked to what extent they were able to apply skills gained in appraisal to improving their professional practice, over 90 percent indicated a positive rating of 3 or higher on a scale of 1 (totally disagree) to 5 (totally agree) (Wellington College of Education, 1999). PMS was achieving its objectives.

In order to provide practical assistance to principals and boards, the TASC team compared the PMS requirements for appraisal with the characteristics of standards assessment. A "fan" model (Figure 2) was then developed to illustrate the range of choices open to school management. ${ }^{1}$ Such an approach is consistent with advice given to boards by the Ministry (MOE, PMS1: Performance Management Systems, 1997b) to consider the options for integrating performance management processes and select one appropriate to the school.

In this model the two axes are mutually supporting and reinforcing. In the open fan, or dual strand approach, appraisal and assessment are two separate performance management processes. This approach is being adopted in a range of medium to large schools but is less well suited to 
Figure 2 A "fan" model for performance management

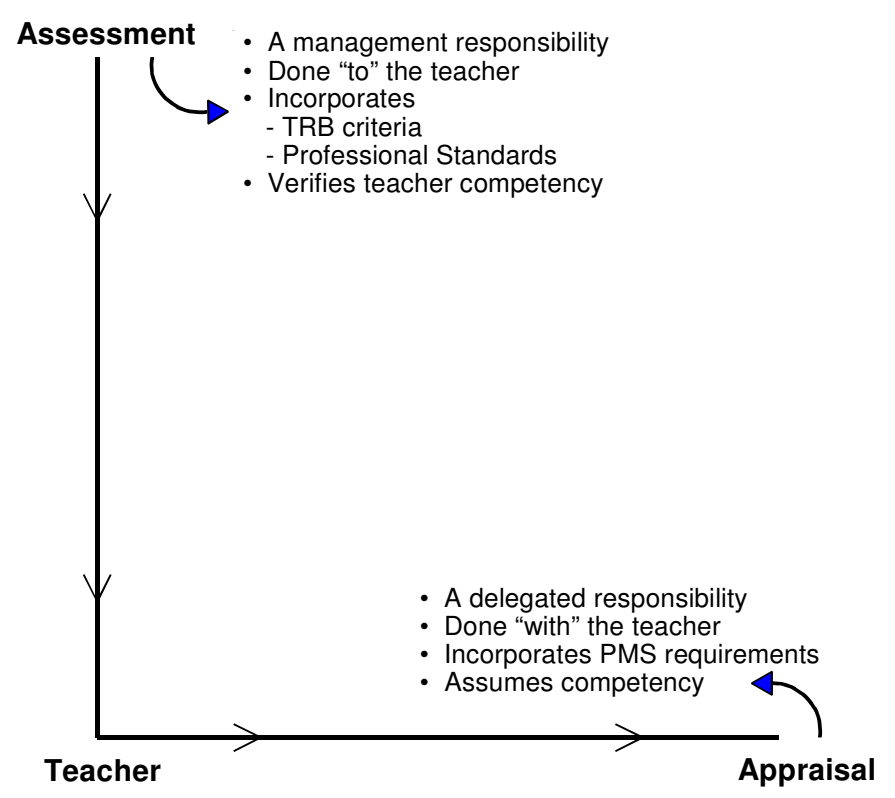

very small primary schools. Some schools using this approach have immature performance management systems and/or low levels of trust between teachers and management. Others have mature, effective appraisal systems with which they are loath to tamper. The dual strand approach provides a clear demarcation between appraisal, in which teachers can step out of their comfort zone and try new things, and assessment where the criteria are fixed. The potential for professional growth is therefore optimised.

The board and management of the Correspondence School have implemented a dual system. The approximately 450 teaching staff select their own appraiser/mentor with whom development objectives, that take into account personal, departmental and school goals are "reality checked" and reviewed. Management staff undertake assessment/ monitoring in relation to professional standards (previously Appendix $G$ for secondary) and TRB requirements. All staff receive training in appraisal skills. Management staff have had training and support for

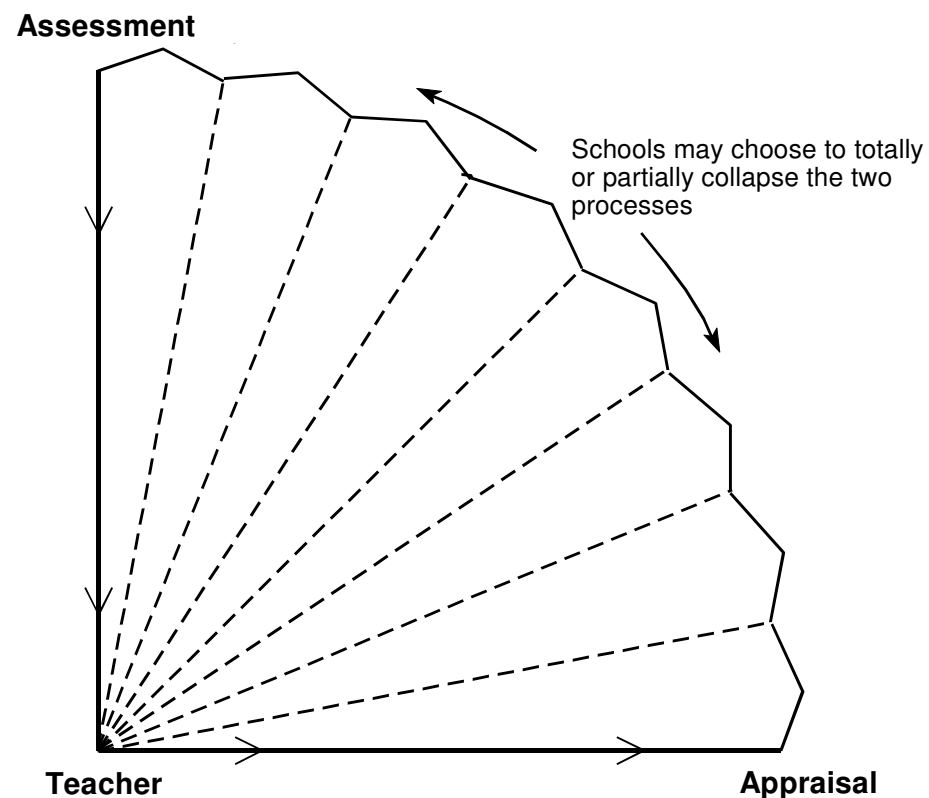

their assessment role. Both systems are subject to on-going monitoring and review to ensure they meet the employer's needs, as well as legal requirements. The Correspondence School's teacher performance management system gained ERO approval in May 1999, having been found to be virtually non-existent just over a year before (ERO, 1999a).

In the closed fan, or single strand model, appraisal and assessment are one process. This approach is the one the Ministry intends schools should adopt (MOE, 1998a). Its main advantage is manageability. One integrated system may be less costly in terms of time, but if the price includes a reduction in teacher commitment to the process then the employer may consider the cost to be high. There is also the question of workload for management staff required to ensure the demands of both appraisal and assessment are met.

In addition to these two approaches, there are options for partially collapsing the "fan". For instance data from a teaching observation may be used for both appraisal and assessment, or an appraisal development objective be generated by assessment outcomes. School management 
needs to consider what type of system will provide a best fit for its school. Factors to be taken into account include:

- school culture: Kura Kaupapa Maori and schools with bilingual and/or immersion classes will want whanau input;

- the nature of the existing appraisal process: A hierarchical system may be better suited to an integrated approach than a "flat" appraisal model that involves peer appraisers;

- staff attitudes to the appraisal process: Teacher co-operation is linked to "their confidence in the validity and fairness of the evaluation/assessment mechanism" (UNESCO World Education Report cited in PPTA, 1999, p. 5). If there is a high level of commitment to appraisal, what impact will a new element have?

- the effectiveness of existing performance management systems: What works well; what can be improved?

- procedures that already exist in regard to attestation: A significant aspect for secondary schools, which have had Appendix G criteria.

\section{Conclusions}

Each board of trustees must ensure its school has a performance management system. The system must incorporate performance appraisal that meets mandatory PMS requirements. It must also ensure teachers meet TRB criteria and Professional Standards.

The Ministry of Education sees no difficulty in incorporating professional standards into teacher appraisal. This is the heart of the issue. Tomorrows' Schools was intended to increase school effectiveness by enabling decision making at a local level. The Ministry reports that feedback from "boards, principals and teachers indicates that performance management systems are making a positive contribution to the quality of teaching in many schools" (NZ Education Gazette, 1999, p. 4). Many principals and trustees are wondering why an additional requirement, which changes the nature of the process, has been imposed just as this progress is being achieved. The risk is that commitment to performance management will give way to compliance with yet another bureaucratic demand that has little "potential to enhance learning outcomes for students" (NZ Education Gazette, 1999, p. 4).

The Ministry's Senior Manager, Medium Term Strategy, has acknowledged some would see the various requirements as inconsistent with self-management, but believes without them, teacher performance management would not have happened (Wood, 1999). Given the ERO findings in 1995 this is a plausible argument. However it is less convincing when a very different type of requirement, based on accountability, is superimposed without consultation, just as schools are starting to get it right.

The proposal to set up a self-monitoring, professional body for teaching, or expand the role of the TRB to achieve the same ends, is yet to be realised. However the Minister of Education has indicated that establishing a teaching council is an early priority for the in-coming government (NZ Education Review, 1999). The consultation process introduced by the previous government as a forerunner to regulatory reform, Legislating for Learning (MOE, 1999d), has been scrapped. The Minister of Education wishes to adopt a "more targeted approach to legislative reform in the school sector " (NZ Education Gazette, 2000, p. 21). This could have significance in terms of the employer role and performance management requirements.

Performance management is just one element of the control exerted by the centre on the self-managing school. Since the appointment of Howard Fancy as Secretary for Education, there has been a move towards a "tight / loose / tight" regulatory environment. By implementing policy controls, which are rigorously monitored for compliance by ERO, boards of trustees theoretically have flexibility to "control" at an individual school level. In reality, the degree of "looseness" may be restricted to the extent that it virtually disappears. In the Chief Review Officer's words, "the tendency to recentralise is a real risk to the basic propositions of Tomorrow's Schools" (1995, cited in ERO, 1999b). Sector groups, and especially the NZ School Trustees' Association, need to actively contribute to the shaping of future regulations if even greater "tightness" is to be averted.

It is also important that what flexibility does remain is fully utilised. Boards can incorporate their strategic direction into a principal's performance agreement based on professional standards. Indicators, for management and teachers, can be linked to expected outcomes that reflect school culture and community wishes, as well as government policy. Boards can encourage teacher involvement in the implementation and review of performance management procedures. Giving teachers input into determining what needs to happen in order for professional standards to be met increases ownership of the process and is consistent with good employer principles. Part of this discussion should 
consider the sources of evidence to be used. By grouping together standards that can be evidenced through written documentation, observation of teaching, or other agreed sources, the process becomes more manageable, and less threatening. It will then be more likely to "channel energies towards the essential rather than the superficial" thus "enhancing and maximising the educational opportunities of pupils" (Mathias \& Jones, 1989).

On the basis of the information presented it is argued that performance management in schools has been made unnecessarily complex by the imposition of three different sets of requirements. These are inconsistent with the ideals of the self-managing school and impinge on the rights of the board as employer. Furthermore, legal prescription may lead to a culture of compliance rather than commitment to professional growth and development. Boards would be well advised to recognise the flexibility the principal has as their chief executive, to adapt legal requirements to the culture of their school. Teacher performance management is an employer responsibility. For teachers, the difficulty is knowing just who that is and what to expect from them.

\section{Note}

1. "Fan" model developed by Wellington College of Education Teacher Appraisal Skills Contract personnel: Tricia Chapman, Jean Martel and Mary Munro, 1998.

\section{References}

Barrington, J. (1998). Central and local control in education. New Zealand Annual Review of Education, 7, 79-93.

Cassis, F. (1999, December 10). Attitude tack. New Zealand Education Review, p. 1.

Cross, B. (1999, September 9). PPTA address to Secondary Principals' Seminar, Wellington College of Education.

Deloitte Touche Tohmatsu. (1994, November). Performance and accountability of primary teachers. Report prepared for the Working Group on Primary Teacher Pay, Performance and Accountability.

Drucker, P. (1954). The practice of management. New York: Harper.

Education Review Office. (1995). Managing staff performance in schools. Autumn series No. 4. Wellington: ERO.

Educational Review Office. (1999a) Confirmed discretionary review report: The Correspondence School. Wellington: ERO.
Educational Review Office. (1999b) ... and talking of Boards of Trustees ... Comments from the Chief Review Officer's strategic overviews in ERO Annual Reports 1989-1999. Wellington: ERO.

Fullan, M. (1991). The new meaning of educational change (2nd ed.). London: Cassel Educational Ltd.

Furukawa, H. (1994). Motivation to work. In Riches, C. \& Morgan, C. (Eds.), Human resource management in education. Chapter 5. Milton Keynes: Open University Press.

Gerritsen, J. (1999, March 29). Standards working well. New Zealand Education Gazette, p. 12.

Gilbert, J., Jones, G., Vitalis, T., Walker, R., \& Gilbertson, D. (1995). Motivation and performance. In Introduction to management in New Zealand (2nd ed.). Chapter 10. Australia: Harcourt Brace \& Co.

Government of New Zealand. (1988). The State Sector Act.

Government of New Zealand. (1989). The Education Act (and Amendments).

Hallinger, P. (1997). Taking charge of change: Surrender! International Studies in Educational Administration, 25(1), 27-34.

Jones J., \& Mathias J. (1994). Staff appraisal training and Total Quality Management. In Doherty, G. (Ed.), Developing quality systems in education. London: Routledge.

Middlewood, D. (1997). Managing appraisal. In Bush, T. \& Middlewood, D., (Eds.), Managing people in education. Chapter 12. London: Paul Chapman Publishing Ltd.

Ministry of Education. (1995). Draft national guidelines for performance management in schools. Wellington: Ministry of Education.

Ministry of Education. (1996). Performance management in schools. New Zealand Gazette, Notice No. 8128, p. 4724.

Ministry of Education. (1997a). Operational funding. Circular. No. 23. p. 2.

Ministry of Education. (1997b). Performance management systems supplements: PMS1 February; PMS2 March; PMS3 May; PMS4 July; PMS5 November. Wellington: Ministry of Education.

Ministry of Education. (1997c, October). Quality teachers for quality learning: A review of teacher education (Green paper). Wellington: Ministry of Education.

Ministry of Education. (1998a, April). Interim professional standards: Primary school deputy/assistant principals, primary school teachers. Wellington: Ministry of Education. 
Ministry of Education. (1998b). Teacher performance management: Primary school teachers, primary school deputy/assistant principals. Wellington: Ministry of Education.

Ministry of Education. (1998c, April 28). Letter to schools from H. Fancy, Secretary for Education.

Ministry of Education. (1998d, September 21). Letter to Wellington College of Education from R. Burbery, Projects \& Contracts Manager, Early Childhood \& Schools Resourcing Division.

Ministry of Education. (1999a, April 28). Meeting of Appraisal Skills contract providers held at the Ministry of Education, Wellington.

Ministry of Education. (1999b, September 9). Presentation to Secondary Principals' Seminar by Rowena Phair, Manager, Early Childhood and Schools Resourcing Division.

Ministry of Education. (1999c, July). Professional standards: criteria for quality teaching. Wellington: Ministry of Education.

Ministry of Education. (1999d) Legislating for Learning. Wellington: Ministry of Education.

New Zealand Educational Institute Te Riu Roa. (1998). Implementing professional standards: A guide for implementing the interim professional standards in the primary teachers, deputy principals, assistant principals and other unit holders' collective employment contract 1998-2000. Wellington: NZEI.

Office of the Minister of Education. (1988). Tomorrow's schools. Wellington: Government Printer.

Post-Primary Teachers' Association. (1999, July). A guide to the implementation of professional standards for secondary teachers criteria for quality teaching. Wellington: PPTA.

Teacher Registration Board. (1997). Handbook: The registration of teachers in Aotearoa New Zealand. Wellington: Teacher Registration Board.

Timperley, H. S. \& Robinson V. H. J. (1996, December.). Appraisal and accountability: Views of secondary school principals. NZ Journal of Educational Administration, 11, 21-28.

Townsend, F. (1998). Appraisal: As a process of betrayal. International Studies in Educational Administration, 26(1), 45-56.

Trethowan D. (1987). Appraisal and target setting: A handbook for teacher development. London: Paul Chapman Publishing Ltd.

Wellington College of Education. (1999). Teacher appraisal skills contract: Milestone 4 report to the Ministry of Education. Wellington: Wellington College of Education.
Wood. D. (1999, May 28) Presentation to students in EDUC 502, Victoria University of Wellington.

\section{The author}

Tricia Chapman became involved in education upon being elected a school trustee in 1989. She served on a primary board for nine years and is currently a trustee of Wellington High School. She works as an Adviser in Educational Management with Wellington College of Education, is Deputy-Chairperson of Wellington/Wairarapa School Trustees' Association and is studying for an MEd at Victoria University of Wellington. 